Research Article

\title{
Influence Factors on General Contractor Capability in the Context of Transforming China
}

\author{
Jie Yang, Hetong Yuan (D, and Lin Zhang \\ School of Management and Engineering, Shandong Jianzhu University, Jinan 250101, China \\ Correspondence should be addressed to Hetong Yuan; yuanht1219@163.com
}

Received 27 April 2020; Revised 6 July 2020; Accepted 14 July 2020; Published 31 July 2020

Academic Editor: Valeria Vignali

Copyright (C) 2020 Jie Yang et al. This is an open access article distributed under the Creative Commons Attribution License, which permits unrestricted use, distribution, and reproduction in any medium, provided the original work is properly cited.

\begin{abstract}
General contracting has gradually become the mainstream mode of project production organizations and the breakthrough point for the transformation of construction industry in China with the deepening of project management and project implementation reform. A general contractor needs to have a clear understanding of the structure and internal mechanism of its capability to achieve sustainable development. This study aimed to explore the critical influencing factors of general contractor capability and interrelationships between these factors in the context of transformation of Chinese construction industry. Fourteen critical factors influencing the general contractor's capability were identified through literature review and questionnaire survey. Then, the interrelationships between factors were revealed through interpretive structural modeling (ISM). The factors were divided into four groups using the Matrice d'Impacts croises-multipication applique a classement (MICMAC) in accordance with driving power and dependence power. The results indicate that particular attention should be paid to enterprise culture at present. A strategy to improve the capability of general contractor was proposed. The results contribute to the construction of the theoretical system of general contractor capability. These research findings can thus act as a practical reference for future research attempting to provide technological and managerial solutions for promoting the development of general contracting.
\end{abstract}

\section{Introduction}

For more than 30 years, rapid economic development in China has provided a huge market for the construction industry and has gradually become a pillar industry of the national economy [1]. In 1984, China's State Council issued Interim Provisions on Management System Reform of the Construction Industry and Capital Construction, where the idea of establishing a general contractor was first proposed. The Chinese government approved nine provinces, including Zhejiang and Jilin, as pilot areas to encourage and develop the mode [2]. In 2016, the Ministry of Housing and Urban-Rural Development issued some opinions on further promoting the development of general project contracting.

China's construction industry is in an important transition period from extensive mode to intensive mode with the deepening supply-side structural reform [3]. Under the guidance and drive of a series of policies, prefabricated building [4, 5], green building [6], information [7], and integration of design and construction [2] are rapidly developed in China. Great opportunities and challenges are faced by general contractors of projects with the transformation and upgrade of the construction industry.

China has exerted vigorous efforts in the development of prefabricated construction. Estimations show that prefabricated buildings will account for $30 \%$ of new construction in a decade with the improvements in the construction industrialization [8]. By contrast, the development of prefabricated construction has accelerated in China [9]. The successful delivery and implementation of prefabricated construction are strongly dependent on the coordination and cooperation between different professionals. Engineering, procurement, and construction (EPC) can address the issues associated with cooperation between the owner, designer, and contractor caused by the shortage of traditional delivery model to a certain extent [4]. In 2019, the Ministry of Housing and Urban-Rural Development issued the general contracting management measures for housing construction and municipal infrastructure projects (draft for comments) and proposed that, in principle, 
prefabricated construction should adopt general contracting and encourage the use of general contracting for government-invested projects. Therefore, pilot project contracting and related policies were launched in Zhejiang, Shanghai, and nine other provinces and cities, focusing on the implementation of general contracting in the areas of housing construction and municipal construction. Digital technology has deeply influenced the construction industry. The development of industry has been successfully promoted by emerging trends, such as building information modeling (BIM), Internet of Things, cloud computing, intelligent construction, and artificial intelligence [10], and the upgrading and development of general contracting.

In this context, the number and requirements of general contracting projects are constantly increasing. On this basis, general contracting has constituted a breakthrough in the transformation of China's construction industry. Compared with developed countries, the business acquisition methods of Chinese enterprises are mainly construction contracting mode and concentrated in the middle- and low-end markets, including Asia, Africa, the Middle East, and Latin America, proving that Chinese enterprises have a large gap with developed countries in terms of scale and capacity [11, 12]. At present, the construction industry is in the transformation stage, and the general contractor cannot turn a blind eye to the continuously changing environment. Clients tend to accelerate project delivery to keep up with the pace of rapid economic and social development simultaneously. Critical challenges and compelling questions are confronted by general contractors in achieving sustainable development of the enterprise itself. Therefore, gaining clear and broad insights into the structure and internal mechanism of enterprise capacity is increasingly needed.

Previous studies mainly focused on the selection of contractors and bidding issues from the perspectives of competitive advantage [13-17] and competitive aggressiveness [18]. They have provided valuable information for evaluating and improving the capability of general contractor enterprises to some extent. However, four issues have been overlooked. First, the selection of contractors starts from the perspective of the owner but fails to study the successful passing of the industrial transformation stage and the pursuit of long-term development from the perspective of the general contractor. Being limited to the present will lead to being eliminated in the future market upgrade and development with the rapid development of industrial technology and management theory. Second, the overall capability of general contractors in China is relatively low. The actual situation of construction industry is inconsistent to equate the capability with competitiveness. Moreover, developing the capability by general project contracting into core competitiveness in short term is unrealistic. Third, previous studies did not investigate the general contractor capability within the context of China, which is a huge and heterogeneous market, and in the transformation phase of construction industry. Fourth, these studies ignored to acknowledge that different types of capability influencing factors are connected but form complex correlations in the completion of general contracting project. Existing research has failed to identify the high priority factors and develop sensible strategies to promote the development of general contractor by neglecting the interrelationships between general contractor capability factors. The research on capability influencing factors is insufficiently comprehensive enough, and the capability level of China's general contractors is uneven. This study aims to fill this gap in the field of construction and engineering management research.

Based on the understanding of the aforementioned limitations existed in previous studies, this study investigates the general contractor capability influencing factors, their interrelationships, and priority levels in the transformation context of China's construction industry. Firstly, from the perspective of general contractors, this paper defines contractor capability based on the whole-life cycle value chain of general contractors. Secondly, two rounds of literature review and questionnaire survey were conducted to determine the influencing factors of general contractor capability against the background of China's construction industry transformation. Finally, this study adopts the Interactive structural modeling (ISM) and matrice d'Impacts croisesmultipication applique a classement (MICMAC) technique to explore the interrelationships among the influencing factors, and the priority level is determined and analyzed in depth. A strategy to improve the capability of general contractors was proposed. The research was conducted with a view to provide a new analytical framework for the general contractors to successfully pass the transformation stage and realize the sustainable development of contractors.

The objectives of this research are (1) defining the capability of the general contractors on the basis of the value chain of general contractors, (2) identifying the critical influencing factors of capability, (3) determining the interactive relationships between these factors, and (4) prioritizing these factors. The specific contributions include the following aspects. First, a general contractor capability framework is developed to improve the contractor capability as a whole, due to the transformation background of construction industry in China. It will help to improve the overall level of project contracting and promote the transformation and development of China's construction industry. Second, this study examines the factors influencing the capability of general contractors in the context of transformation of Chinese construction industry, which is beneficial to understand the unique in China's construction and engineering management practice.

\section{Capability of General Contractor Based on Value Chain}

2.1. Connotation of General Contracting. EPC contract mode is defined as a contracting method of conducting the entire process management of design, procurement, and construction of a project and taking responsibility for the quality, safety, construction period, and project cost in accordance with the contracts signed with construction units [19]. In particular, the owners entrust the overall design, procurement, and construction to general contractors, and they then decide whether to subcontract the design and 
construction works to subcontractors. Comprehensive principles and approaches can be adopted by the owners to manage the project. Construction, equipment purchase, and installation are closely related to the design of large-scale industrial investment projects with the core technology of technological process, such as oil, railway, and water conservancy projects. The EPC contract mode can effectively shorten the construction period through simultaneous design, procurement, and construction [20]. In engineering practice, the EPC contract mode has been widely used [21] and achieved remarkable results in several engineering areas [22]. Therefore, the research scope of this study refers to the EPC contract mode.

2.2. Definition of General Contractor. Most studies in China and Korea have proposed the term of general contractors and other countries called it as big or large construction contractors [23]. A general contractor shall complete the project on schedule with the right quality and shall comply with local laws and regulations during its implementation to protect the environment without harming the interests of the owners, local communities, and employees [24]. A construction company needs an effective strategy to survive in this highly competitive global era [25]. Although a large profit occurs in the project implementation of international EPC, the general contractors have to face the huge risks and challenges simultaneously in this progress. These risks and challenges caused by different stakeholders and the complex environment can impose major pressure on the inevitable threat to project performance [26, 27]. Therefore, identifying the capabilities of the general contractor helps in determining the benchmarks for a useful development strategy.

\subsection{Life Cycle Value Chain-Based General Contractor Ca-} pability Analysis. Capability refers to the extent in which companies are organized to achieve the project outcome [28] that provides competitive advantage for themselves in the international market [29]. The existing literature usually adopts literature review to define the capability of project contractors [30-32]. It can be seen that the research on the capability of general contractors is insufficient, and the identification method of capability is relatively general. Therefore, a clear, systematic, and comprehensive analysis method is needed to clarify the capability of the general contractor. The value realization process should be first defined to define the capability of the general contractor. Professor Michael E. Porter deems that the value chain consists of a series of value creation activities that can meet the requirements of customers. As a result, this paper introduces the value chain theory to the general contractor, combines the literature review, and rebrands capability of the general contractor based on the whole-life cycle value chain.

The value chain of the general contractor based on the entire life cycle refers to the value creation chain that connects all links in the life cycle of the project to realize the value of construction products or related services. The value chain is divided into basic and supporting value activities in accordance with Porter's value chain model and the characteristics of the general contractor. Fundamental value activities cover the enterprise value chain and promote the solution, creation, and realization of stakeholder needs. Supporting value activities assists basic value activities to ensure the normal operation of an enterprise and to achieve the set goals on the basis of providing powerful resources.

The business process of the general contractor in the life cycle is as follows: project contracting-project consulting-design-procurement-construction-completion acceptance and handover in the project trading market formed by the owner and the contractor. The basic value activities of the general contract are analyzed on the basis of the above process.

2.3.1. Project Contracting. Project contracting is a prerequisite for operation and production and refers to the process of an enterprise for obtaining the project construction right. This process involves identifying relevant information from the trading market, gaining knowledge about the owner needs, and developing a feasibility plan by analyzing the enterprise capability. The general contractor needs to master the design, construction, and other technologies and market to ensure that the main chain of production and operation of the enterprise is not broken.

2.3.2. Project Consulting. Consulting includes project planning, feasibility study, and project financing. It is the decisive stage of the entire process of project management. The fineness and comprehensiveness of preliminary demonstration work have an important influence on project management in the project implementation and operation stage.

2.3.3. Design. Design generally includes preliminary and construction drawing designs. The design work in prefabricated buildings is more complex than in traditional projects [5]. In addition to the complexity of component design itself, the transportation, placement, and assembly of components need to be considered [33]. The integrated design process in the design phase is the key to the successful implementation of strategies and technologies in green building projects [34].

2.3.4. Procurement. Procurement is the acquisition of materials and the recruitment of technical personnel, design, and subcontracting of the project phase. Procurement connects with the design and construction of EPC project and has important influence and restriction on the design and construction [35]. Procurement accounts for more than $50 \%$ of the total project cost.

2.3.5. Construction. Construction involves the flow of employees, money, materials, equipment, and information of the general contractor, which is the key to creating value for the general contractor. A general contractor may undertake 
the construction by himself or may choose to subcontract the work to a subcontractor for managing the construction in a targeted and principled manner.

2.3.6. Completion Acceptance and Handover. The construction results are accepted, and the project is delivered to the owner after meeting the acceptance.

The value chain of an EPC contractor refers to the above basic value activities and includes supporting value activities to support the basic value activities. Under the EPC contract mode, supporting value activities include technological innovation, enterprise infrastructure, information resource management, and human resource management.

2.3.7. Technological Innovation. Driven by a new round of industrial revolution, new equipment, new materials, and new technology are emerging in the construction industry. Owners must improve the technical standards of contracting enterprises. Using new technology and construction process and focusing on technological development and innovation are an effective method for the general contractor to obtain high-quality products and cost advantages.

2.3.8. Enterprise Infrastructure. The general contractor of a project has a strong dependence on internal and market resources. The enterprise infrastructure can be applicable and provide strong support for the value chain only when this characteristic is fully considered in the formulation of the organizational structure, corporate culture, and other policies.

2.3.9. Information Resource Management. The supply information of materials or equipment plays a vital role in inventory decision-making and affects the construction schedule and the performance of the project and the general contractor [36]. The general contractor must attach importance to the value of information resources and apply information management technology to provide scientific information support for correct decision-making.

2.3.10. Human Resource Management. Interviews with quantity surveyors and contractors have identified confusion in staffing as the main cause of rework because of low skill levels [37]. Furthermore, the transfer of knowledge and skills is remarkably and constructively influenced by managers, executives, and supervisors [38]. Therefore, the general contractor must perform well in human resource planning, personnel recruitment, and training and cultivate a group of experienced management talents who master technology, management, finance, and law to effectively control the project.

Thus, the value chain of the general contractor based on the life cycle can be constructed, as shown in Figure 1.

Soft power in an enterprise is a key capability in obtaining the value recognition from different stakeholders and in inspiring stakeholders to produce the expected behavior of the enterprise to achieve the enterprise purpose through the possession, transformation, and dissemination of specific resources of the enterprise [39]. This study introduces the concept of soft power into the general contractor value chain to extract the soft power of general contractors. The core business work links of production and construction entities are extracted and defined as business capability, and the ability of assisting enterprises to complete business is defined as auxiliary capability through the analysis of basic and supporting value activities. The general contractor capability is defined as collections of business capability, auxiliary capability, and soft power of the general contractor. This paper introduces the theory of value chain and soft power and, compared with the existing literature, provides a more comprehensive and systematic analysis thinking for clarifying the capability of general contractor. Meanwhile, the process of defining the capability of the general contractor is more clearly. The identification of capability influencing factors needs to be further analyzed.

\section{Research Methodology}

This study followed a three-step research design to achieve the targets of this research, as shown in Figure 2. First, a tworound systematic literature review was conducted to identify the influencing factors to the general contractor capability. Next, a questionnaire survey was performed to elicit the perceptions of experts regarding the associated relationships between these factors. The hierarchical structure of influencing factors can be depicted through ISM. The final step was classifying these factors in accordance with driving power and dependence power using the MICMAC technique.

3.1. ISM. Some techniques, such as analytic network process (ANP), system dynamics (SD), and ISM, are available to assess the interrelationships among factors. ANP can be used to analyze the interrelationships and priorities of factors in a complex system. Portillo et al. [40] determined the prioritize rural development strategies by ANP methodology. However, ANP cannot completely display all types of dependencies because it is generally difficult to rule out the possibility of interactions within the criteria cluster [41]. SD is also used to analyze the conduction relationship between the factors. Nasirzadeh et al. [42] focus on the dependency and feedback relationship among risk factors. Although SD has developed quantitative criteria for mathematical equations to represent dependencies between factors, the complexity of policy modeling makes SD complex and limited. To sum up, ANP and SD reflect the correlation among factors to a certain extent but cannot clearly show the hierarchical conduction structure and the types of influencing factors. At the same time, some research techniques are too complicated. Therefore, ISM was the preferred method in this study, as it enables insights into the direct and direct interrelationships between various factors with ranking and direction [43]. 


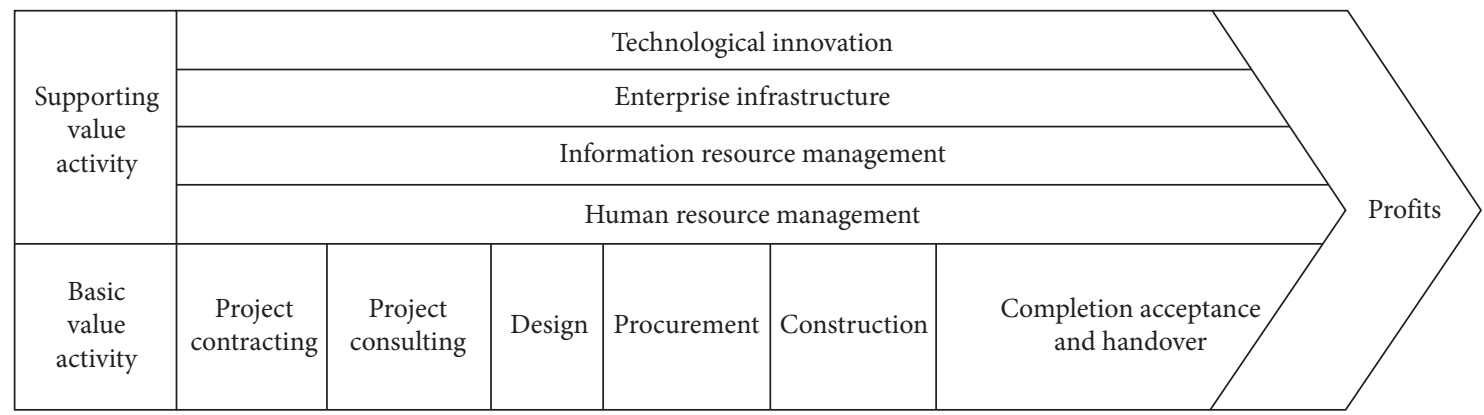

FIgURE 1: The value chain of the general contractor.

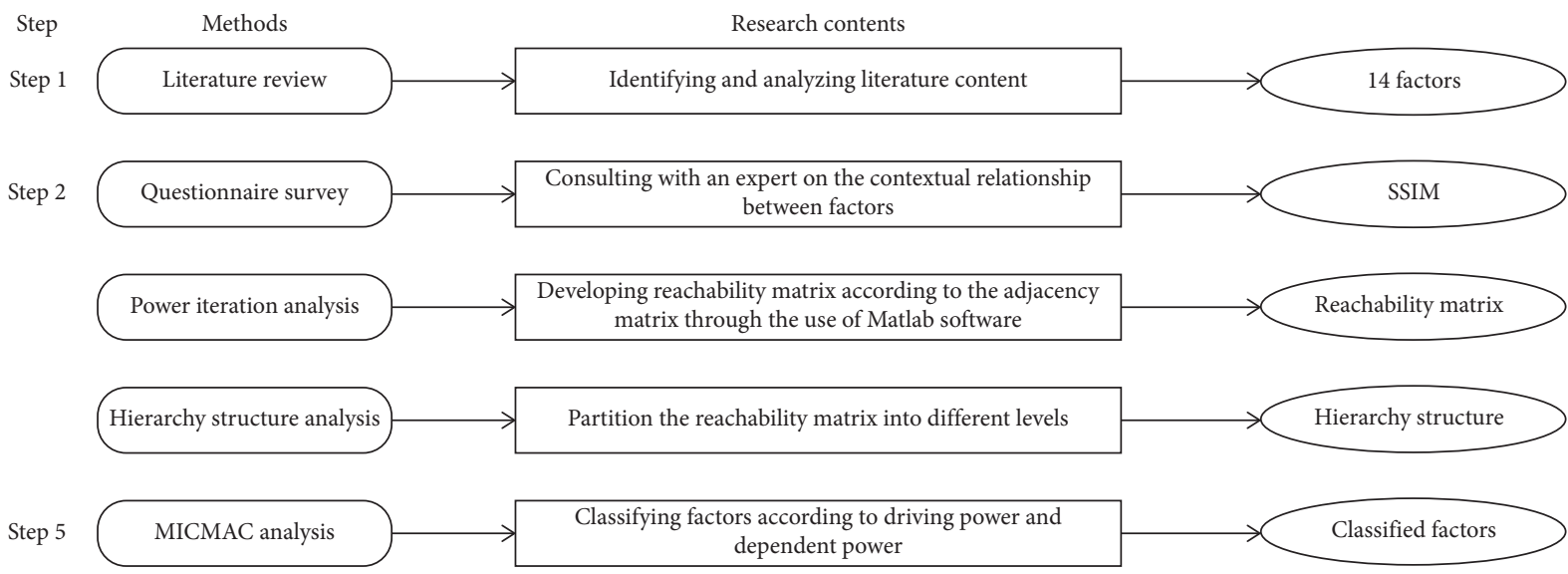

Figure 2: Procedures of this research.

ISM is a method used to analyze complex systems. The concrete idea is to determine the interdependent relationship between elements on the basis of expert experience and knowledge and to establish a multilevel structural model with the help of computer technology $[44,45]$. In the research of construction and engineering management, ISM has been used in many studies, such as the study of the interactions among barriers to off-site construction in China [46] and the interaction structure between construction project risk factors [47, 48]. ISM can solve the internal correlation between the factors affecting the capability of general contractor.

3.2. MICMAC. In this study, MICMAC was used to complement the ISM. MICMAC represents the crosseffect matrix multiplication applied to classification which is a structural analysis model for analyzing the driving power and dependence power of model elements [49]. The driving power of a factor refers to the total number of other factors it affects, and the dependence power suggests the total number of other factors it is affected by [50]. ISM and MICMAC have similar calculating procedures where they both apply a structural analysis matrix. Therefore, MICMAC can be combined with ISM to analyze the principal and passive relationship of influencing factors of general contractor capability based on ISM [48]. This will further help to identify the key factors affecting the capability of the general contractor.

3.3. Questionnaire Survey. A questionnaire survey was conducted in Shandong Province, China. Because the urbanization level, development pattern and economic structure of Shandong Province are very representative of China in all provinces of China, making many scholars consider that Shandong Province is the epitome of China's development [51, 52]. Moreover, Shandong Province has many construction projects, high-production value, large general contracting scale, and good policy conditions [53]. The Department of Housing and Construction of Shandong Province issued "The circular on organizing and recommending the general project contracting and the entire process consultation service pilot project (the third batch)" in 2019. The policy points out that new housing construction and municipal engineering projects within the administrative area of Shandong Province can apply for general contracting pilot projects to promote general contracting and open up a green channel for pilot project, quick review, and handling. Therefore, the research results obtained by questionnaire survey in Shandong Province have guiding significance for other regions.

A snowball sampling was employed to recruit experts with rich knowledge and expertise in the field of general contracting. A total of fourteen experts were contacted 
through telephone and e-mail, and six experts agreed to participate in this study. Liu et al. [54] point out that, in construction research, meaningful results can be obtained when sampling using well-established selection criteria. The profiles of participated experts are shown in Table 1. The six experts were asked to judge whether the factors identified by literature review are reasonable and comprehensive in the transition context of China. The connotation of each of these factors is confirmed and agreed in Section 4. All experts undertook pairwise comparison of the influencing factors by answering the question "do you think factor $i$ directly affects factor $j$ ?" However, different experts may have varying judgments. Therefore, the contextual relationship between factors in this study was determined when more than half of the experts agree.

\section{Literature Review of Influencing Factors to General Contractor Capability}

To identify factors influencing the general contractor, a systematic method was adopted in this research to search and review related literature. The literature review in this research was conducted for two rounds. In the first round, the Google Scholar research engine was used to search relevant publications by setting the keywords including "capability," "capacity," "general contractor," and "influencing factors." However, only a limited number of studies investigating factors influencing the capability of general contractor were found. Thus, a second round of literature review was conducted to identify many potential factors affecting the capability of general contractor. The keywords used for the second round include "contractor," "competitiveness," "capacity," and "capability." The factors influencing the capability of the general contracting enterprises were identified on the basis of systematically and simultaneously reviewing the indexed literature and the above analysis toward the value chain given the market circumstances of the Chinese construction industry in the transition context. Through the above process, a total of fourteen factors influencing the capability of general contractor were identified. Luo et al. [55] classified the core competitiveness of construction enterprises according to business ability, auxiliary ability, and soft power. Wang et al. [56] divided the influencing factors of construction industry competitiveness into hard power and soft power. According to the definition of general contractor capability based on value chain and soft power theory in Section 2, this paper classifies the fourteen influencing factors of capability in accordance with business capability, auxiliary capability, and soft power, as shown in Table 2.

\subsection{Business Capability Influencing Factors}

4.1.1. Financing Capacity (B1). The investment in EPC projects is large. Project owners usually require the general contractor to raise capital for relieving short-term capital pressure, solving the problem of capital source, reducing their debt ratio, and avoiding the corresponding financing risk. Compared with the financing system of developed countries, the policy capital support system of China is imperfect in terms of credit and insurance [70]. General contractors frequently need to finance part of the capital.

4.1.2. Green Construction Capacity (B2). At this stage, environmental friendliness and sustainable development are the principles that all industries follow. This study proposes the green construction capacity based on overall national interests. Green construction is proposed as a clean construction measure that heavily relies on adopting green materials and economical equipment. Superior green construction capacity is claimed to provide numerous environmental and economic advantages [6] and is highly conducive to supporting the sustainable development of EPC enterprises. Health and safety executive (HSE) management is a common concern of project stakeholders [32], and the HSE management system is incorporated into the green construction capacity.

4.1.3. Design Capacity (B3). EPC mode is the design-led vertical integration of the value chain general contract-driven mode. The design phase plays a decisive role in the total cost and construction difficulty of the construction project. In the early decision-making stage, the design management and construction scheme of the project are analyzed to improve the success rate. The backward extension through the design work can guide the procurement of materials. Changes in the construction process can be avoided through the reasonable design of the technical scheme.

4.1.4. Building-Supply Capacity (B4). Referring to the concept of supply chain management [71], building-supply capacity refers to the ability of contractors to control the purchase and movement of multiparty building material resources, such as suppliers and subcontractors, with the ultimate goal of reducing the costs incurred by the supply chain. Supply-side reform is a hot topic in China today. It aims to change the current situation of oversupply, waste of resources, low product quality, and low added value [72]. Building-supply capacity can help promote environmental compliance and improve environmental performance of enterprises, thereby accelerating the transformation of Chinese enterprises in the global value chain [73].

4.1.5. Project Management Capacity (B5). Project management capacity refers to the ability of an enterprise to stabilize its goals, coordinate tasks, and visions and optimize the allocation of resources to maintain its competitive advantage [74]. With the continuous scarcity of human resources, project management can be perceived as a competitive advantage that has remarkably increased and resulted in favorable performance in the last two decades. In an international general contracting project, the contractor usually needs to solve the huge risks in the estimation, financing, design, procurement, construction, and its interface [75]. Enterprises can mitigate the risks posed by project implementation and shift from risk costs to profit margins to optimize their efficiency and 
TABle 1: Profile of experts.

\begin{tabular}{lccc}
\hline Expert & Employer & Role & Years of experience \\
\hline A & Research institution & Professor & 7 \\
B & Research institution & Professor & 6 \\
C & Research institution & Professor & 10 \\
D & Construction company & General manager & 8 \\
E & Design institute & Professional engineer & 9 \\
F & Construction company & General manager & 12 \\
\hline
\end{tabular}

TABLE 2: Factors influencing the capability of general contractor.

\begin{tabular}{|c|c|c|c|c|c|}
\hline Categories & No. & Factors & Implications & Sources & Frequency \\
\hline \multirow{5}{*}{$\begin{array}{l}\text { Business } \\
\text { capability }\end{array}$} & B1 & Financing capacity & The ability to acquire long-term quality capital & $\begin{array}{l}1-3,7,12,15 \\
17\end{array}$ & 7 \\
\hline & B2 & $\begin{array}{l}\text { Green construction } \\
\text { capacity }\end{array}$ & $\begin{array}{l}\text { The construction capacity to minimize resources and reduce } \\
\text { negative impacts on the environment while ensuring basic } \\
\text { requirements such as quality and safety }\end{array}$ & $\begin{array}{l}4,7,10 \\
12-15\end{array}$ & 7 \\
\hline & B3 & Design capacity & $\begin{array}{c}\text { Process and engineering design capacity, optimization of } \\
\text { design scheme, research on constructability of design } \\
\text { scheme, and design communication within the whole- } \\
\text { construction cycle }\end{array}$ & $1,3,4,6$ & 4 \\
\hline & B4 & Building-supply capacity & $\begin{array}{c}\text { The ability to control procurement and movement of } \\
\text { building materials }\end{array}$ & $\begin{array}{l}1,2,9-11 \\
13-15\end{array}$ & 8 \\
\hline & B5 & $\begin{array}{l}\text { Project management } \\
\text { capacity }\end{array}$ & $\begin{array}{l}\text { The ability of an enterprise to stabilize its goals, coordinate } \\
\text { tasks and visions, and optimize the allocation of resources to } \\
\text { maintain its competitive advantage }\end{array}$ & $\begin{array}{c}1,3,7,8, \\
10-13,15,16\end{array}$ & 10 \\
\hline \multirow{5}{*}{$\begin{array}{l}\text { Auxiliary } \\
\text { capability }\end{array}$} & B6 & $\begin{array}{l}\text { Financial management } \\
\text { capacity }\end{array}$ & $\begin{array}{c}\text { The ability to coordinate and control the financial } \\
\text { management cycle and integrate the complete financial } \\
\text { management system }\end{array}$ & $\begin{array}{l}3,6,8,9,10 \\
13-15,17\end{array}$ & 9 \\
\hline & B7 & $\begin{array}{l}\text { Human resource } \\
\text { management capability }\end{array}$ & $\begin{array}{l}\text { The ability to effectively apply human resources through } \\
\text { recruitment, selection, training, remuneration, and other } \\
\text { management forms }\end{array}$ & $\begin{array}{l}1,2,7,8 \\
10-15,17\end{array}$ & 11 \\
\hline & B8 & Information application & $\begin{array}{l}\text { The ability to apply information technology to engineering } \\
\text { construction }\end{array}$ & $2-4,7-9$ & 6 \\
\hline & B9 & $\begin{array}{l}\text { Organizational } \\
\text { management level }\end{array}$ & $\begin{array}{l}\text { The rationality of organizational structure, position, and } \\
\text { authority-responsibility relationship }\end{array}$ & $\begin{array}{l}1,3,8,10,15 \\
17\end{array}$ & 6 \\
\hline & $\mathrm{B} 10$ & $\begin{array}{l}\text { Communication and } \\
\text { coordination capacity }\end{array}$ & $\begin{array}{c}\text { The ability to properly handle relationships with } \\
\text { stakeholders }\end{array}$ & $\begin{array}{c}1,6,8-11,13 \\
15,16\end{array}$ & 9 \\
\hline \multirow{4}{*}{ Soft power } & B11 & Innovation capacity & $\begin{array}{l}\text { The innovation capacity of products and building technology } \\
\text { and the research input to the innovation area }\end{array}$ & $\begin{array}{l}2-4,7-9,12 \\
15\end{array}$ & 8 \\
\hline & $\mathrm{B} 12$ & Enterprise culture & $\begin{array}{c}\text { A spiritual content to help enterprises constantly adjust their } \\
\text { strategies and organizational models, cultivate and improve } \\
\text { their transformation capabilities, and realize sustainable } \\
\text { development of enterprises }\end{array}$ & $2,3,10$ & 3 \\
\hline & $\mathrm{B} 13$ & $\begin{array}{l}\text { Sustainable development } \\
\text { capability }\end{array}$ & $\begin{array}{l}\text { The ability to rationally utilize resources and protect the } \\
\text { ecological environment }\end{array}$ & 10,12 & 2 \\
\hline & B14 & Social influence & $\begin{array}{l}\text { The public's understanding and recognition of the general } \\
\text { contractor, the scope of market activities, and the level of } \\
\text { enterprise qualification }\end{array}$ & $3,4,13-17$ & 7 \\
\hline
\end{tabular}

Note. 1, [57]; 2, [58]; 3, [55]; 4, [59]; 5, [18]; 6, [60]; 7, [32]; 8, [61]; 9, [23]; 10, [62]; 11, [63]; 12, [64]; 13, [65]; 14, [66]; 15, [67]; 16, [68]; 17, [69].

sustainability and benefit the stakeholders through the effective methods of project management.

\subsection{Auxiliary Capability}

4.2.1. Financial Management Capacity (B6). Financial management capacity refers to the ability to coordinate and control the cycle process of enterprise financial management and integrate the complete financial management system.
EPC contractors fund the purchase of large equipment and materials and act as payers during the design and construction stages. Weak financial management capacity of EPC contractors may lead to the shortage of materials, production equipment, and qualified labor in the project implementation that will hinder the effective implementation of construction projects. Beatham et al. [76] and Naoum [77] pointed out that financial availability and sufficient cash flow of enterprises can improve performance and profitability. 
4.2.2. Human Resource Management Capacity (B7). A research on the strategic management practices of construction companies found that the quality and experience of company personnel is the largest advantage over competitors [78]. Forceful human resource management system is a key element of the most valuable asset, new source of wealth, and competitive advantage of a construction company [79] because the productivity of a company is closely related to its strategy [80]. EPC projects involve members of different teams, ranks, and domains, and the delay in project progress is because of insufficient human resources in many cases [81].

4.2.3. Information Application (B8). Information application refers to the application of information technology in engineering construction. Its core is the application of BIM and includes information technologies, such as the Internet of Things and radio frequency. The information obtained from these technologies can be well connected, shared among the stakeholders, and provide a basis for real-time visibility and traceability of the entire processes of construction management. High complexity and difficult coordination are typical features of EPC projects [82]. Collaborative cooperation based on BIM platform can be realized in project construction, such as deepening design and resource management. $4 \mathrm{D}$ BIM is developed [83] that can enhance the understanding of construction plan, simplify the spatiotemporal relationship of construction activities, and support multiparty information sharing through $4 \mathrm{D}$ visualization [84].

\subsubsection{Organizational Management Level (B9).} Organizational management level is reflected in the general contractor's organizational structure, where various control processes and methods are scientific and feasible. The project participator is unfamiliar with the business field outside the company whether the EPC contractor is in the form of a consortium or subcontracted. In particular, no standardized operation process is reported within the organization, reasonable internal project organization pattern, arrangement of business division, and resource coordination [30]. The construction of flexible organization and efficient management team is beneficial in improving the organizational management level of the general contractor and is valuable in preventing the high profit from being consumed by the enterprise's extremely large scale [85].

4.2.5. Communication and Coordination Capacity (B10). In recent years, the increasing complexity and specialization of large-scale construction projects have led to a surge in subcontractor recruitment, thereby forcing the general contractor to focus on coordination with subcontractors. The bidding strategy of subcontractor is influenced by all aspects of the subcontractor-general contractor relationship [86]. General contractors, not only subcontractors, must manage the relationship with various stakeholders, including customers, creditors, designers, and suppliers [87].
These stakeholders are frequently a key source of risk and have valuable resources to reduce it [88]. The enterprise must rely on external skills and knowledge in response to the rapidly changing technology environment. Interenterprise cooperation is an important tool for creating technological capabilities. Cooperative enterprises can only achieve their goals through information exchange, negotiation, and coordination [61].

\subsection{Soft Power}

4.3.1. Innovation Capacity (B11). The production and research and development capacity of a country or organization are crucial from the perspective of construction project contracting development [89]. The innovation consciousness of construction enterprise has become inevitable. Construction enterprises can increase sales and gain competitiveness by developing unique technical features [38]. Furthermore, adopting innovative products and processes can directly improve the achievement of product and enterprise goals because they can reduce project cost and duration [90]. Low investment in innovation in the construction industry leads to miserable productivity growth in general contracting [91].

4.3.2. Enterprise Culture (B12). Enterprise culture is a unique configuration of norms, values, beliefs, and behavior developed by enterprises through solving its internal integration and external adaptation problems [92]. Its characteristics reflect the means that groups and individuals jointly complete tasks [93]. Abeysekera [94] consider that enterprise culture comprises the strategies, goals, and values about the characteristics of the construction industry, construction methods, ability of employees, and work organization. In the context of this study, the general contracting enterprise culture refers to a spiritual content that helps enterprises to correct the strategy and organizational model, improve the transformation capability, and achieve sustainable development. Therefore, enterprise culture can be used as a maturity scale for enterprises to conduct selfrestraint, self-revision, and self-improvement [30].

\subsubsection{Sustainable Development Capacity (B13).} Construction activity has a significant influence on the environment [95]. Contractors should be responsible for reducing negative effects on the environment and society, and construction clients are increasingly demanding that contractors adopt sustainable development strategies in their construction processes. Companies with good environmental and social governance can protect their valuable reputations [96]. Tan et al. [17] indicated that the contribution of sustainable development performance to the future enterprise competitiveness is great although no unique relationship is found between the two variables of sustainable development performance and enterprise competitiveness. 
4.3.4. Social Influence (B14). The social influence of the general contractor includes its market activity scope and share, public reputation, and enterprise qualification level. The share of the general contractor in the international market is an important indicator of its enterprise capability; however, the degree of internationalization of Chinese contractors is low, and the high-end market share is low [97]. Reputation and impression are reflections of the successful experience of the projects undertaken by construction enterprises. The general contractor shall have the design and construction qualifications appropriate to the scale of the project, or the design and construction units with the corresponding qualification shall form a consortium [98]. Therefore, the qualification level of general contracting enterprises plays an important role in the contract of general contracting projects.

\section{Results}

5.1. Factors Influencing the Capability of General Contractor. The factors influencing the capability of general contractor identified in Section 4 were distributed to experts. Positive feedback was received, and no change was made to the list of influencing factors. The experts were asked to list the interrelationships between pairs of factors. The collected answers were interpreted by the authors to find the contextual relationship between factors and input the results into the structural self-interaction matrix (SSIM).

5.2. SSIM. In this study, the interrelationship between factor $i$ and $j$ is represented by four symbols:

$V$ : factor $i$ led to factor $j$

$A$ : factor $j$ led to factor $i$

$X$ : factors $i$ and $j$ reach each other

$O$ : factors $i$ and $j$ are independent of each other

A SSIM is established on the basis of the above rules (Table 3).

5.3. Reachability Matrix. A reachability matrix is established by SSIM in two steps. In accordance with the rules in Table 4, each item of SSIM information is converted into a binary format (that is, 1 or 0 ) to obtain the adjacency matrix.

The adjacency matrix is shown in Table 5 .

The transitivity of the contextual relation is a basic assumption in ISM. For instance, B1 (financing capability) is related to B2 (design capability), and B1 (financing capability) is related to B3 (green construction capability). Thus, $\mathrm{B} 2$ and B3 are necessarily related. The reachability matrix is obtained with the aid of the computation tool Matlab in conducting a power iteration analysis (Table 6).

5.4. Level Partitions. The reachability and antecedent sets of each factor can be obtained from the reachability matrix. The reachability set $\mathrm{R}(\mathrm{Bi})$ of element $\mathrm{Bi}$ consists of the elements influenced by $\mathrm{Bi}$, including element $\mathrm{Bi}$ itself. The antecedent set $\mathrm{A}(\mathrm{Bi})$ of element $\mathrm{Bi}$ consists of the elements that can affect $\mathrm{Bi}$, including $\mathrm{Bi}$ itself. The intersection of $\mathrm{Bi}$ reachability set and antecedent set is denoted as $C$, that is, $C=$. Element $\mathrm{Bi}$ is considered a top-level element of the ISM digraph when $C=\mathrm{R}(\mathrm{Bi})$. The top-level elements are removed in subsequent analysis. In accordance with the above principle, the obtained top-level elements must be eliminated layer by layer until the last element is identified.

The levels and corresponding set of each element are shown in Table 7.

The hierarchical relationships of the factors influencing the capability of general contractor can be obtained in accordance with the level partitions and reachability matrix. The 14 capability influencing factors are divided into four levels of the ISM, as shown in Figure 3. An arrow points from factor $i$ to factor $j$, indicating that factor $i$ can result in factor $j$, and a two-way arrow shows a mutual influence.

In the ISM model, the factors with high-level position are easily affected by the factors below the level, whereas the factors with low-level position will influence the factors above the level. As shown in Table 7 and Figure 3, the factors influencing the capability of general contractor in Chinese transformation context are indicated in the ISM, clearly and directly showing the interaction between all influencing factors:

(1) Level 5 B12 (enterprise culture) is located at the bottom of ISM hierarchy, indicating that it affects other factors directly or indirectly and plays a certain guiding role in the development of general contractor. Therefore, B12 is a primary factor that should be focused on improving the capability of Chinese general contractors.

(2) Nine factors occupy the middle portion (levels 2 and 3) of the ISM ranging from B7 (human resource management capacity), B14 (social influence), B11 (innovation capacity), B3 (design capacity), B2 (green construction capacity), B8 (information application), B4 (building-supply capacity), B10 (communication and coordination capacity), and B5 (project management capacity). The middle portion is also the core portion covering the entire life cycle of project general contracting. Levels 2 B7 (human resource management capacity) and B14 (social influence) connect levels 1 and 3. Similarly, level 3 B11 (innovation capacity), B3 (design capacity), B2 (green construction capacity), B8 (information application), B4 (building-supply capacity), B10 (communication and coordination capacity), and B5 (project management capacity) connect levels 2 and 4 . The middle portion factors play a connecting role in the hierarchical structure, suggesting that they are affected by the factors in the lower level and can control the top-level factors upward. In this study, the factors in the middle portion have a feedback influence on themselves. 
TABLE 3: SSIM.

\begin{tabular}{|c|c|c|c|c|c|c|c|c|c|c|c|c|c|c|}
\hline & B14 & B13 & B12 & B11 & B10 & B9 & B8 & B7 & B6 & B5 & B4 & B3 & B2 & $\mathrm{B} 1$ \\
\hline B1 & A & $\mathrm{O}$ & $\mathrm{O}$ & $\mathrm{O}$ & A & $\mathrm{O}$ & $\mathrm{O}$ & $\mathrm{O}$ & $\mathrm{O}$ & $\mathrm{O}$ & $\mathrm{O}$ & $\mathrm{O}$ & $\mathrm{O}$ & \\
\hline B2 & V & V & $\mathrm{O}$ & A & $\mathrm{O}$ & $\mathrm{O}$ & A & $\mathrm{O}$ & $\mathrm{O}$ & A & A & $\mathrm{X}$ & & \\
\hline B3 & $\mathrm{V}$ & V & $\mathrm{O}$ & V & $\mathrm{O}$ & $\mathrm{O}$ & A & $\mathrm{O}$ & $\mathrm{O}$ & $\mathrm{O}$ & $\mathrm{V}$ & & & \\
\hline B4 & $\mathrm{O}$ & $\mathrm{O}$ & $\mathrm{O}$ & $\mathrm{O}$ & A & $\mathrm{O}$ & A & $\mathrm{O}$ & $\mathrm{O}$ & A & & & & \\
\hline B5 & $\mathrm{O}$ & $\mathrm{O}$ & $\mathrm{O}$ & $\mathrm{O}$ & A & $\mathrm{A}$ & A & $\mathrm{O}$ & $\mathrm{O}$ & & & & & \\
\hline B6 & $\mathrm{O}$ & $\mathrm{O}$ & $\mathrm{O}$ & $\mathrm{O}$ & $\mathrm{O}$ & $\mathrm{O}$ & A & A & & & & & & \\
\hline B7 & $X$ & $\mathrm{O}$ & A & $\mathrm{O}$ & $\mathrm{O}$ & $\mathrm{O}$ & A & & & & & & & \\
\hline B8 & $\mathrm{O}$ & $\mathrm{O}$ & $\mathrm{O}$ & $\mathrm{O}$ & $\mathrm{V}$ & $\mathrm{O}$ & & & & & & & & \\
\hline B9 & $\mathrm{O}$ & $\mathrm{O}$ & $\mathrm{O}$ & $\mathrm{O}$ & $\mathrm{O}$ & & & & & & & & & \\
\hline B10 & $\mathrm{O}$ & $\mathrm{O}$ & $\mathrm{O}$ & $\mathrm{O}$ & & & & & & & & & & \\
\hline B11 & $\mathrm{O}$ & $\mathrm{V}$ & $\mathrm{O}$ & & & & & & & & & & & \\
\hline B12 & $\mathrm{O}$ & $\mathrm{O}$ & & & & & & & & & & & & \\
\hline B13 & $\mathrm{O}$ & & & & & & & & & & & & & \\
\hline B14 & & & & & & & & & & & & & & \\
\hline
\end{tabular}

TABle 4: Substitution rule.

\begin{tabular}{lcc}
\hline SSIM & & Adjacency matrix \\
& $(i, j)$ & $(j, i)$ \\
\hline$V$ & 1 & 0 \\
$A$ & 0 & 1 \\
$X$ & 1 & 1 \\
$O$ & 0 & 0 \\
\hline
\end{tabular}

(3) B6 (financial management capacity), B1 (financing capacity), B13 (sustainable development capacity), and B9 (organizational management level) are at the top levels of the ISM hierarchy, and the improvement in these factors is largely dependent on other influencing factors.

5.5. MICMAC Analysis. The MICMAC was used to analyze the driving power and dependence power of each factor. In the reachability matrix, the calculated driving power and dependence power of each element are provided in the last row and column, respectively. Following the classification adopted by previous researchers [99], the MICMAC diagram is divided into four groups, namely, autonomous, dependent, linkage, and driver factor groups. The driving power and dependence power of the influencing factors of the general contractor's capability are shown in Figure 4.

(1) Autonomous factors have weak driving power and dependence power and are less associated with the system, as presented in quadrant I. No autonomous factors are found in this model, indicating that all factors are reasonably identified and affect the capability of general contractor to a certain extent.

(2) Dependent factors have strong dependence power and weak driving power, which are presented in quadrant II. B1 (financing capacity), B6 (financial management capacity), B9 (organizational management level), B13 (sustainable development capacity), B7 (human resource management capacity), and B14 (social influence) have strong dependence on other factors.

(3) Linkage factors have strong driving power and strong dependence power and are presented in quadrant III. B2 (design capacity), B3 (green construction capacity), B4 (building-supply capacity), B5 (project management capacity), B8 (information application capacity), B10 (communication and coordination capacity), and B11 (innovation capacity) have a relative effect on the ultimate goal and have a feedback effect on themselves.

(4) Independent factors have strong driving power and weak dependence power and are presented in quadrant IV. B12 (enterprise culture) is an independent variable in the MICMAC analysis. Independent factors consistently appear at the bottom of the ISM digraph.

\section{Discussion}

6.1. Result Analysis and Discussion. The ISM hierarchical structure determines the hierarchical relationship of each influencing factor. The results of MICMAC analysis complement the ISM by identifying the driving power and dependence power. Combined with these results, the priority level of factors can be obtained to help general contractors in identifying the key factors of high priority for capability improvement and effectively developing and improving actions and strategies.

Figures 3 and 4 show that B12 (enterprise culture) is located at the bottom of ISM hierarchy and has the highest driving power. Therefore, top priority should be given to enhance the enterprise culture in the general contractor capability improvement work. The result confirms the finding of previous studies. For example, Zhenghang et al. [100] believe that enterprise culture is the most important core capability factor for the long-term development of large international engineering contractors. As shown in Table 7, enterprise culture has a positive effect on other factors, which is consistent with previous studies [101-103]. 
TABLE 5: Adjacency matrix.

\begin{tabular}{lccccccccccccccc}
\hline & B1 & B2 & B3 & B4 & B5 & B6 & B7 & B8 & B9 & B10 & B11 & B12 & B13 & B14 \\
\hline B1 & 1 & 0 & 0 & 0 & 0 & 0 & 0 & 0 & 0 & 0 & 0 & 0 & 0 \\
B2 & 0 & 1 & 1 & 0 & 0 & 0 & 0 & 1 & 0 & 0 & 0 & 0 & 1 \\
B3 & 0 & 1 & 1 & 1 & 0 & 0 & 0 & 1 & 0 & 0 & 1 & 0 & 1 \\
B4 & 0 & 1 & 0 & 1 & 0 & 0 & 0 & 0 & 0 & 0 & 0 & 0 & 0 \\
B5 & 0 & 1 & 0 & 1 & 1 & 0 & 0 & 0 & 1 & 0 & 0 & 0 & 0 & 0 \\
B6 & 0 & 0 & 0 & 0 & 0 & 1 & 0 & 0 & 0 & 0 & 0 & 0 & 0 \\
B7 & 0 & 0 & 0 & 0 & 0 & 1 & 1 & 0 & 0 & 0 & 0 & 0 & 0 \\
B8 & 0 & 1 & 1 & 1 & 1 & 1 & 1 & 1 & 0 & 1 & 0 & 0 & 0 \\
B9 & 0 & 0 & 0 & 0 & 0 & 0 & 0 & 0 & 1 & 0 & 0 & 0 & 0 \\
B10 & 1 & 0 & 0 & 1 & 1 & 0 & 0 & 0 & 0 & 1 & 0 & 0 & 0 \\
B11 & 0 & 1 & 0 & 0 & 0 & 0 & 0 & 0 & 0 & 0 & 1 & 0 & 0 \\
B12 & 0 & 0 & 0 & 0 & 0 & 0 & 1 & 0 & 0 & 1 & 0 & 1 & 0 \\
B13 & 0 & 0 & 0 & 0 & 0 & 0 & 0 & 0 & 0 & 0 & 0 & 0 & 0 \\
B14 & 1 & 0 & 0 & 0 & 0 & 0 & 1 & 0 & 0 & 0 & 0 & 0 & 0 \\
\hline
\end{tabular}

Table 6: Reachability matrix.

\begin{tabular}{lccccccccccccccc}
\hline & B1 & B2 & B3 & B4 & B5 & B6 & B7 & B8 & B9 & B10 & B11 & B12 & B13 & B14 & Driving power \\
\hline B1 & 1 & 0 & 0 & 0 & 0 & 0 & 0 & 0 & 0 & 0 & 0 & 0 & 0 & 0 \\
B2 & 1 & 1 & 1 & 1 & 1 & 1 & 1 & 1 & 1 & 1 & 1 & 0 & 1 & 1 & 1 \\
B3 & 1 & 1 & 1 & 1 & 1 & 1 & 1 & 1 & 1 & 1 & 1 & 0 & 1 & 1 \\
B4 & 1 & 1 & 1 & 1 & 1 & 1 & 1 & 1 & 1 & 1 & 1 & 0 & 1 & 1 \\
B5 & 1 & 1 & 1 & 1 & 1 & 1 & 1 & 1 & 1 & 1 & 1 & 0 & 1 & 1 & 13 \\
B6 & 0 & 0 & 0 & 0 & 0 & 1 & 0 & 0 & 0 & 0 & 0 & 0 & 0 & 0 & 13 \\
B7 & 1 & 0 & 0 & 0 & 0 & 1 & 1 & 0 & 0 & 0 & 0 & 0 & 0 & 1 \\
B8 & 1 & 1 & 1 & 1 & 1 & 1 & 1 & 1 & 1 & 1 & 1 & 0 & 1 & 1 & 4 \\
B9 & 0 & 0 & 0 & 0 & 0 & 0 & 0 & 0 & 1 & 0 & 0 & 0 & 0 & 0 \\
B10 & 1 & 1 & 1 & 1 & 1 & 1 & 1 & 1 & 1 & 1 & 1 & 0 & 1 & 1 \\
B11 & 1 & 1 & 1 & 1 & 1 & 1 & 1 & 1 & 1 & 1 & 1 & 0 & 1 & 1 \\
B12 & 1 & 1 & 1 & 1 & 1 & 1 & 1 & 1 & 1 & 1 & 1 & 1 & 1 & 1 \\
B13 & 0 & 0 & 0 & 0 & 0 & 0 & 0 & 0 & 0 & 0 & 0 & 0 & 1 & 0 & 13 \\
B14 & 1 & 0 & 0 & 0 & 0 & 1 & 1 & 0 & 0 & 0 & 0 & 0 & 0 & 1 \\
Dependence power & 10 & 8 & 8 & 8 & 8 & 11 & 10 & 8 & 9 & 8 & 8 & 1 & 9 & 1 \\
\hline
\end{tabular}

TABLE 7: Level partitioning factors.

\begin{tabular}{lcccc}
\hline Factor & $\begin{array}{c}\text { Reachability } \\
\text { set }\end{array}$ & Antecedent set & $\begin{array}{c}\text { Intersection } \\
\text { set }\end{array}$ & Level \\
\hline B1 & 1 & $1-5,7,8,10-12$, & 1 & 1 \\
B2 & $1-11,13,14$ & $2-5,8,10-12$ & $2-5,8$ & 3 \\
B3 & $1-11,13,14$ & $2-5,8,10-12$ & $2-5,8$ & 3 \\
B4 & $1-11,13,14$ & $2-5,8,10-12$ & $2-5,8$ & 3 \\
B5 & $1-11,13,14$ & $2-5,8,10-12$ & $2-5,8$ & 3 \\
B6 & 6 & $2-8,10-12,14$ & 6 & 1 \\
B7 & $1,6,7,14$ & $2-5,7,8,10-12$, & 7,14 & 2 \\
B8 & $1-11,13,14$ & $2-5,8,10-12$ & $2-5,8,10$ & 3 \\
B9 & 9 & $2-5,8-12$ & 9 & 1 \\
B10 & $1-11,13,14$ & $2-5,8,10-12$ & $2-5,8,10$ & 3 \\
B11 & $1-11,13,14$ & $2-5,8,10-12$ & $2-5,8,10$ & 3 \\
B12 & $1-14$ & 12 & 12 & 4 \\
B13 & 13 & $2-5,8,10-12,13$ & 13 & 1 \\
B14 & $1,6,7,14$ & $2-5,7,8,10-12$, & 7,14 & 2 \\
\hline
\end{tabular}

Enterprise culture plays a deep guiding role in the development of the general contractor in the transformation stage. A good enterprise culture enables employees to have a sense of identity and responsibility for the company, which is conducive for employees to take the initiative to complete their work. Enterprise culture influences the perceptions of employees, customers, and other stakeholders and governs enterprise operations and internal processes. However, many obstacles are found in the promotion of enterprise culture in practice. On the one hand, enterprise culture as soft power is easily and superficially ignored. On the other hand, construction projects are different in terms of size, location, participants, and subcontracting level [104], indicating that different cultural orientations exist. Project participants should consider these cultural orientations and take necessary measures to mitigate the consequences of any undesirable culture. In accordance with the characteristics of the Chinese national culture, the employees of Chinese organizations usually follow the formal authority role [105] and consider that the rules set by the senior management must be diligently obeyed. Li [106] agreed with this view and pointed out that enterprise culture is the culture of employees, and the integration of enterprise culture and staff spirit is important in the fusion of culture and enterprise work. In China, Liu et al. [107] assumed that the focus of construction companies in a 


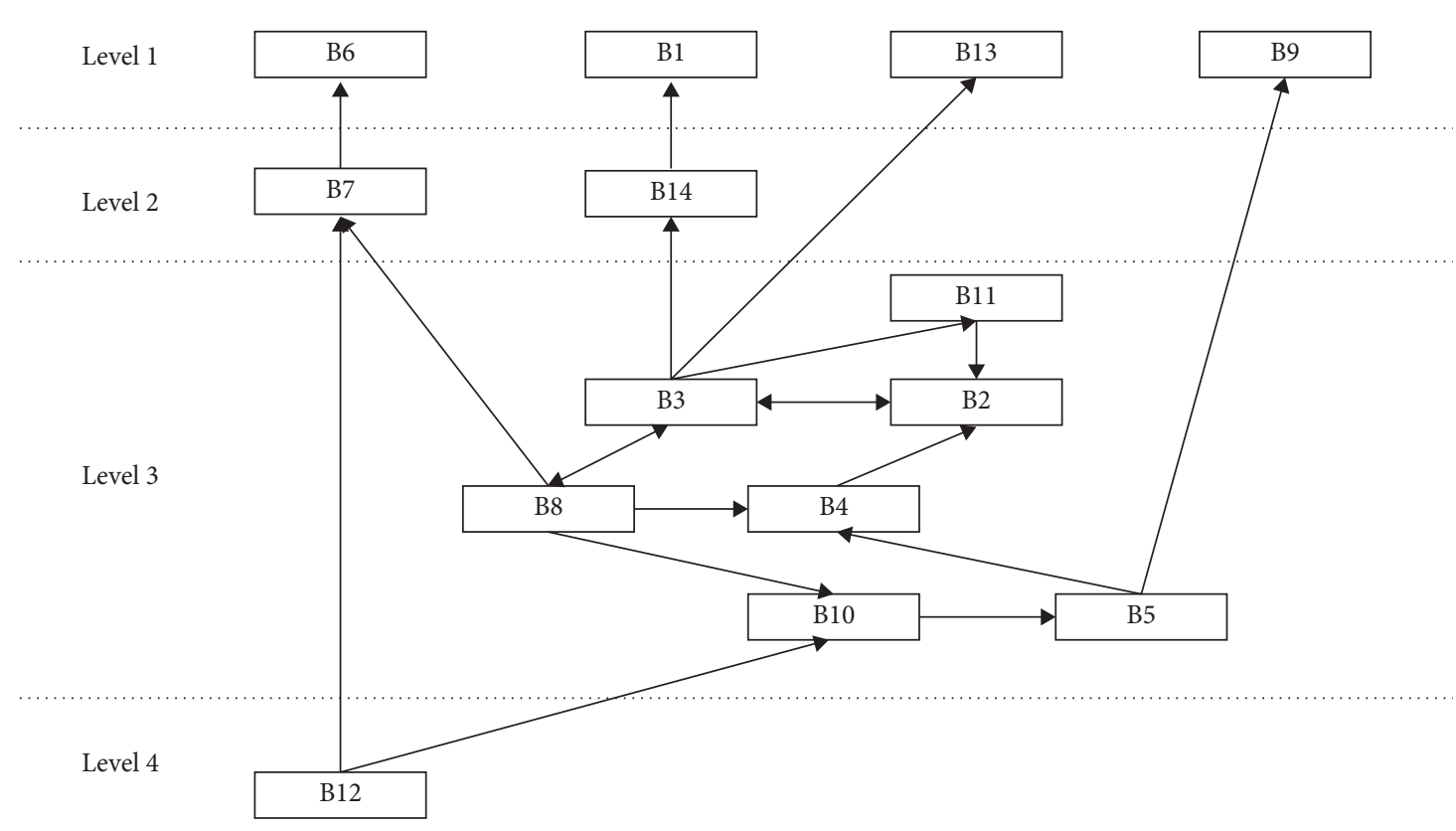

FIGURE 3: ISM of factors influencing the capability of general contractor.

\begin{tabular}{|c|c|c|c|c|c|c|c|c|c|c|c|c|c|c|}
\hline 14 & B12 & & & & \multirow{2}{*}{\multicolumn{3}{|c|}{$\begin{array}{l}\text { Independent } \\
\text { factor } \\
\text { IV }\end{array}$}} & & & & & \multirow{2}{*}{\multicolumn{3}{|c|}{$\begin{array}{l}\text { Linkage } \\
\text { factor } \\
\text { III }\end{array}$}} \\
\hline 13 & & & & & & & & \multirow[t]{2}{*}{$\begin{array}{l}\text { B2, B3, } \\
\text { B4, B5 } \\
\text { B8, B10, } \\
\text { B11 }\end{array}$} & & & & & & \\
\hline 12 & & & & & & & & & & & & & & \\
\hline 11 & & & & & & & & & & & & & & \\
\hline 10 & & & & & & & & & & & & & & \\
\hline 9 & & & & & & & & & & & & & & \\
\hline 8 & & & & & & & & & & & & & & \\
\hline 7 & & & & & & om & & & & & & $\mathrm{De}$ & ident & \\
\hline 6 & & & & & & & & & & & & $\begin{array}{l}\text { fac } \\
\text { II }\end{array}$ & & \\
\hline 5 & & & & & & & & & & & & & & \\
\hline 4 & & & & & & & & & & B7, B14 & & & & \\
\hline 3 & & & & & & & & & & & & & & \\
\hline 2 & & & & & & & & & & & & & & \\
\hline 1 & & & & & & & & & $\begin{array}{l}\text { B9, } \\
\text { B13 }\end{array}$ & B1 & B6 & & & \\
\hline & 1 & 2 & 3 & 4 & 5 & 6 & 7 & 8 & 9 & 10 & 11 & 12 & 13 & 14 \\
\hline
\end{tabular}

FIGURE 4: Results of MICMAC analysis of factors.

market economy system will shift from internal process systems that define rules and procedures to interpersonal relationships that emphasize commitment, participation, and self-development. Therefore, the cultural construction of enterprises should consider the personal quality and interpersonal relationship of employees and guide the choice of employees to align with the vision of the enterprise. 
B2 (design capacity), B3 (green construction capacity), B4 (building-supply capacity), B5 (project management capacity), B8 (information application), B10 (communication and coordination capacity), and B11 (innovation capacity) located at the core portion of the hierarchy level are perceived with the second highest driving power, indicating that these factors should be prioritized. As shown in Figure 3 and Table 5, the seven linkage factors (B2, B3, B4, B5, B8, $\mathrm{B} 10$, and B11) have a direct effect on the upper factors. This is consistent with previous studies $[11,32,60,61]$, regarding the positive effect of such influencing factors on capability of contractors. For instance, design capacity (B2) and green construction capacity (B3) located at level 3 are vital guarantees for the general contractor to complete the project on schedule and with the desired quality, thereby helping to improve the enterprise contracting qualification and enhancing social influence (B14) at level 2, which will affect B7 (human resource management capacity). The general contracting project is fully undertaken by the general contractor, and the linkage factors approximately cover the entire life cycle of the project and interact with each other. For instance, the main feature of the general contracting project is the intersection of design and construction depth. On the one hand, good design capacity is an important guarantee of construction operability, and reasonable design scheme can avoid many changes during construction. On the other hand, excellent construction capacity has a positive effect on improving design capacity. Critical issues and errors that significantly exist in construction drawings are identified by the reasonable study of technical personnel, thereby achieving technology progress by solving the problems. B8 interacts with the same-level factors. In EPC projects, controlling the design, procurement, and construction schedule are challenging for the general contractor [108]. Capacities of BIM in process integration and information sharing can help solve such problems. Currently, most companies use BIM for visualization and constructability purposes and plans to use the software for estimation and cost control in the future [109]. BIM can be used to detect design conflicts in the process of deepening design for solving the problems before construction [2]. The performance of factors at levels 1 and 2 can be increased accordingly when the linkage factors can be improved through interaction.

B9 (organizational management level), B13 (sustainable development capacity), B1 (financing capacity), and B6 (financial management capacity) located at level 1 have high dependence power and weak driving power. This finding indicates that these factors are susceptible for the influence of linkage and independent factors. As Shen et al. [50] have pointed out, the dependence factors can be effectively improved when independent factors can be well promoted. Therefore, enterprises can appropriately reduce the attention of such factors and focus on the factors with high driving power. Then, B9 (organizational management level), B13 (sustainable development capacity), B1 (financing capacity), and B6 (financial management capacity) can be considered as the favorable results of other factors. This view is supported by other scholars $[17,110]$. For instance, the performance of B13 (sustainable development capacity) is heavily influenced by B11 (innovation capacity). In particular, the improvement of technology and mode caused by developing and investing innovative resources can achieve the coupling between environmental pollution and economic development, thereby realizing the sustainable development of construction companies [111]. The performance of organizational management level (B9), financing capacity (B1), and financial management capacity (B6) will be improved accordingly when sustainable development capacity (B13) is strongly supported by innovation activities (B11).

6.2. General Contractor Capability Improvement Strategy. Based on the above discussion, the interrelationship and priority of the factor influencing the capability of the general contractor are determined. This is helpful to put forward the strategy of capability improvement in combination with the actual project, so as to promote the development of the general contractor. First, enterprise culture has the highest priority in the system of influencing factors of general contractor capability. Therefore, the general contractor should pay attention to the cultivation and promotion of enterprise culture. Second, in accordance with the original nature of the main business, the Chinese general contractor should improve the capability through construction or design of two paths. The advantage of the general contractor developed by the design institute is that it has the design capacity (B3) but lacks the understanding and experience of the EPC project management. Therefore, general contractors should focus on the improvement of green construction capacity (B2) and project management capacity (B5) during the transition period. Meanwhile, such general contractors should stick to technological innovation and improve their innovation capacity (B11). Contractors should insist on continuous innovation of their traditional technology, establish institutions to develop patented technology, lead the industry in science and technology, and strive for competitive advantage [112]. The general contractor developed from the construction enterprise is strong in project construction management and construction capacity (B2). However, such general contractors are weak in design. Meanwhile, due to the influence of many factors, such as the centralization of enterprise organization and management and internal coordination ability, it is difficult to effectively integrate internal resources, undertake the heavy responsibility of completing the whole-construction cycle management, and realize the matrix organizational structure of international construction and engineering companies [113]. Therefore, the improvement of its overall contracting comprehensive capability should be started from three aspects, namely, design capacity (B3), innovation capacity (B11), and organizational management level (B9). The capacities proposed above are not only in urgent need of cultivation but also in the lower level of ISM model and have a strong driving power. The promotion of such linkage factors will effectively support the improvement of highlevel factors through influence transmission. 
From a managerial point of view, the above research findings are helpful for the general contracting practitioners to better understand the internal structure of contractor capability and provide new ideas for formulation of contractor development path. Meanwhile, contractors can better cultivate core competitiveness, so as to promote the development of general contracting and steadily promote the transformation of the construction industry.

\section{Conclusions}

To the best of our knowledge, this research attempts for the first time to conduct a study on the factors influencing the capability of general contractor in the context of China's construction industry transformation. This research identified fourteen factors. The fourteen factors were divided into four different levels in a hierarchy in accordance with ISM analysis. Then, six dependent factors, seven linkage factors, and one independent factor were identified in accordance with their driving power and dependence power through MICMAC analysis. The results suggest that the effectiveness of promoting the capability of the general contractor largely depends on enterprise culture. Other factors with high influence power, such as innovation capacity, design capacity, green construction capacity, information application, building-supply capacity, communication and coordination capacity, and project management capacity, should be investigated. On this basis, the development strategies of construction enterprises with different backgrounds are put forward.

ISM method reveals the structural relationship of the identified capability influencing factors, which are substantially conducive for the general contractor to effectively develop strategy formulation. According to MICMAC analysis, the driving power and dependent power provide insights into resource allocation priority. The improvement in driving power will promote the development of other influencing factors. The theoretical contributions of this research are as follows: (1) capability of the general contractor from the perspective of the whole-life cycle value chain is defined, (2) analysis system of capability influencing factors is established using the ISM method combined with MICMAC analysis, which contributes to the knowledge body by providing an indepth understanding of interactive relationships among capability influencing factors in the context of transformation of the Chinese construction industry, and (3) the findings of this study are consistent with existing studies, which validates the capability analysis methodology proposed.

Although the purpose of this study has been achieved, there are still some limitations. First, the research results are generated in the context of the construction industry transformation stage in China. The factors and dimensions need to be refined for implementation in other contexts (developed or developing countries). Second, the developed model is derived from opinions of experts, which are in limited number and come from the same region. Therefore, future research opportunities also exist for quantifying the interrelations between influencing factors of general contractor capability with additional samples on a national scale.

\section{Data Availability}

The data used to support the findings of this study are included within the article.

\section{Conflicts of Interest}

The authors declare that there are no conflicts of interest.

\section{References}

[1] H. Shen, Y. Peng, and C. Guo, "Analysis of the evolution game of construction and demolition waste recycling behavior based on prospect theory under environmental regulation," International Journal of Environmental Research and Public Health, vol. 15, no. 7, p. 1518, 2018.

[2] J.-X. Guo, C.-M. Hu, and R. Bao, "Predicting the duration of a general contracting industrial project based on the residual modified model," KSCE Journal of Civil Engineering, vol. 23, no. 8, pp. 3275-3284, 2019.

[3] R. Zhang, G. Li, A. L. Li, and H. D. Yu, "A statistical study on the growth model of China's manufacturing industry under the background of supply-side reform," Statistics and Decision Making, vol. 17, no. 34, pp. 141-145, 2018, in Chinese.

[4] Y. Chang, X. Li, E. Masanet, L. Zhang, Z. Huang, and R. Ries, "Unlocking the green opportunity for prefabricated buildings and construction in China," Resources, Conservation and Recycling, vol. 139, pp. 259-261, 2018.

[5] H. Wu, Q. K. Qian, A. Straub, and H. Visscher, "Exploring transaction costs in the prefabricated housing supply chain in China," Journal of Cleaner Production, vol. 226, pp. 550-563, 2019.

[6] Q. Shi, J. Zuo, R. Huang, J. Huang, and S. Pullen, "Identifying the critical factors for green construction-an empirical study in China," Habitat International, vol. 40, pp. 1-8, 2013.

[7] Y. Zhang, H. Luo, and Y. He, "A system for tender price evaluation of construction project based on big data," Procedia Engineering, vol. 123, pp. 606-614, 2015.

[8] The State Council, Suggestions on Further Strengthening the Management of Urban Planning and Construction, The State Council, Beijing, China, 2016.

[9] J. Hong, G. Q. Shen, Z. Li, B. Zhang, and W. Zhang, "Barriers to promoting prefabricated construction in China: a costbenefit analysis," Journal of Cleaner Production, vol. 172, pp. 649-660, 2018.

[10] M. Bilal, L. O. Oyedele, J. Qadir et al., "Big data in the construction industry: a review of present status, opportunities, and future trends," Advanced Engineering Informatics, vol. 30, no. 3, pp. 500-521, 2016.

[11] C. Wen and M. Xiao, "Studying the development method of general contractor of China," in Proceedings of the 2010 International Conference on Mechanic Automation and Control Engineering, pp. 872-875, IEEE, Wuhan, China, June 2010.

[12] Z. Wang, G. Yang, and W. Hong, Construction Project Transaction Theories and Modes, China Waterpower Press, Beijing, China, 2010.

[13] M. Safa, A. Shahi, C. T. Haas et al., "Competitive intelligence (CI) for evaluation of construction contractors," Automation in Construction, vol. 59, pp. 149-157, 2015. 
[14] W. K. Fu, D. S. Drew, and H. P. Lo, "The effect of experience on contractors' competitiveness in recurrent bidding," Construction Management and Economics, vol. 20, no. 8, pp. 655-666, 2002.

[15] H.-J. Kim and K. F. Reinschmidt, "Effects of contractors' risk attitude on competition in construction," Journal of Construction Engineering and Management, vol. 137, no. 4, pp. 275-283, 2011.

[16] Y. Tan, L. Shen, and C. Langston, “Contractors' competition strategies in bidding: Hong Kong study," Journal of Construction Engineering and Management, vol. 136, no. 10, pp. 1069-1077, 2010.

[17] Y. Tan, L. Shen, and H. Yao, "Sustainable construction practice and contractors' competitiveness: a preliminary study," Habitat International, vol. 35, no. 2, pp. 225-230, 2011.

[18] H. Setiawan, B. Erdogan, and S. O. Ogunlana, "Competitive aggressiveness of contractors: a study of Indonesia," Procedia Engineering, vol. 125, no. 5, pp. 68-74, 2015.

[19] The Ministry of Housing and Urban-Rural Construction, Opinions on Further Promoting the Development of General Project Contracting, The Ministry of Housing and UrbanRural Construction, Beijing, China, 2016.

[20] F. F. Wu and H. X. Lu, "Study on operation mode and applicability of EPC project," Journal of Southeast University (Philosophy and Social Sciences), vol. s1, pp. 65-66, 2015, in Chinese.

[21] Q. Guo, Z. P. Xu, G. F. Zhang, and T. T. Tu, "Comparative analysis between the EPC contract mode and the traditional mode based on the transaction cost theory," in Proceedings of 2010 IEEE the 17th International Conference on Industrial Engineering and Engineering Management, vol. 1, Xiamen, China, October 2010.

[22] J. S. Shane, S. M. Bogus, and K. R. Molenaar, "Municipal water/wastewater project delivery performance comparison," Journal of Management in Engineering, vol. 29, no. 3, pp. 251-258, 2013.

[23] S. Haghbin and P. Davoudi, "Investigation of similarities between collaborative network and general contractors-literature review," Procedia Technology, vol. 16, pp. 979-987, 2014.

[24] H. Zhang, "Design management under international EPC contract mode," International Economic Cooperation, vol. 72015, in Chinese.

[25] F. A. Orozcol, A. F. Serpell, K. R. Molenaar, and E. Forcael, "Modeling competitiveness factors and indexes for construction companies: findings of Chile," Journal of Water Resources Planning and Management, vol. 140, no. 4, 2014.

[26] D. Lei, W. Tang, C. Liu, S. Wang, and Y. Zhou, "Enhancing engineer-procure-construct project performance by partnering in international markets: perspective from Chinese construction companies," International Journal of Project Management, vol. 34, no. 1, 2015.

[27] R. Pal, P. Wang, and X. Liang, "The critical factors in managing relationships in international engineering, procurement, and construction (IEPC) projects of Chinese organizations," International Journal of Project Management, vol. 35, no. 7, pp. 1225-1237, 2018.

[28] S. Graham, A. D. David, and K. Hanspeter, Strategy and Capability: Sustaining organizational change, Blackwell Publishing, Oxford, UK, 2003.

[29] W. S. DeSarbo, C. Anthony Di Benedetto, M. Michael Song, and I. Sinha, "Revisiting the Miles and Snow strategic framework: uncovering interrelationships between strategic types, capabilities, environmental uncertainty, and firm performance," Strategic Management Journal, vol. 26, no. 1, pp. 47-74, 2005.

[30] Z. H. Lin, M. S. Qiang, and S. N. Yuan, "Evaluation of core competency model for large international engineering contractors," Journal of Tsinghua University (Natural Science), vol. 12, p. 7, 2015, in Chinese.

[31] S. Xia, "Construction and application analysis of contractor capability index system and evaluation model," China Management Science, vol. 20, no. S1, pp. 74-79, 2012, in Chinese.

[32] T. Wang, W. Tang, L. Du, C. F. Duffield, and Y. Wei, "Relationships among risk management, partnering, and contractor capability in international EPC project delivery," Journal of Management in Engineering, vol. 32, no. 6, Article ID 04016017, 2016.

[33] J. T. O’Connor, W. J. O’Brien, and J. O. Choi, “Industrial project execution planning: modularization versus stickbuilt," Practice Periodical on Structural Design and Construction, vol. 21, no. 1, Article ID 04015014, 2016.

[34] Y. H. Ahn, C. W. Jung, M. Suh, and M. H. Jeon, "Integrated construction process for green building," Procedia Engineering, vol. 145, pp. 670-676, 2016.

[35] X. H. Wu, "Practice and innovation in purchasing management of large overseas petroleum and petrochemical EPC projects," Building Economy, vol. 40, no. 9, pp. 63-66, 2019, in Chinese.

[36] J. U. Min and H. C. Bjornsson, "Agent-based construction supply chain simulator (CS2) for measuring the value of realtime information sharing in construction," Journal of Management in Engineering, vol. 24, no. 4, pp. 245-254, 2008.

[37] S. H. Han, D. Y. Kim, and H. Kim, "Predicting profit performance for selecting candidate international construction projects," Journal of Construction Engineering and Management, vol. 133, no. 6, pp. 425-436, 2007.

[38] S. Y. Park and Y. S. Kim, "Correlations between construction firm value and top management characteristics," Journal of Management in Engineering, vol. 36, no. 2, Article ID 04019041, 2020.

[39] G. Q. Huang, J. F. Xu, T. Jiang, and H. Xi, "Research on the connotation, forming process and function mechanism of enterprise soft power," Soft Science, vol. 22, no. 2, pp. 127131, 2008, in Chinese.

[40] L. F. Portillo, O. Nekhay, and L. E. Mohedano, "Use of the ANP methodology to prioritize rural development strategies under the LEADER approach in protected areas," The Case of Lagodekhi, Georgia, Land Use Policy, vol. 88, Article ID 104121, 2019.

[41] W.-W. Wu, "Choosing knowledge management strategies by using a combined ANP and DEMATEL approach," Expert Systems With Applications, vol. 35, no. 3, pp. 828-835, 2008.

[42] F. Nasirzadeh, A. Afshar, and M. Khanzadi, "System dynamics approach for construction risk analysis," International Journal of Civil Engineering, vol. 6, no. 2, pp. 120-131, 2008.

[43] R. Attri, N. Dev, and V. Sharma, "Interpretive structural modelling (ISM) approach: an overview," Research Journal of Management Sciences, vol. 23191171 pages, 2013.

[44] J. N. Warfield, "Developing subsystem matrices in structural modeling," IEEE Transactions on Systems, Man, and Cybernetics, vol. SMC-4, no. 1, pp. 74-80, 1974. 
[45] S. Jharkharia and R. Shankar, "Selection of logistics service provider: an analytic network process (ANP) approach," Omega, vol. 35, no. 3, pp. 274-289, 2007.

[46] X. Gan, R. Chang, J. Zuo, T. Wen, and G. Zillante, "Barriers to the transition towards off-site construction in China: an Interpretive structural modeling approach," Journal of Cleaner Production, vol. 197, no. 1, pp. 8-18, 2018.

[47] H. Etemadinia and M. Tavakolan, "Using a hybrid system dynamics and interpretive structural modeling for risk analysis of design phase of the construction projects," International Journal of Construction Management, vol. 18, pp. 1-20, 2018.

[48] L. Guan, A. Abbasi, and M. J. Ryan, "Analyzing green building project risk interdependencies using interpretive structural modeling," Journal of Cleaner Production, vol. 256, Article ID 120372, 2020.

[49] S. Chandramowli, M. Transue, and F. A. Felder, "Analysis of barriers to development in landfill communities using interpretive structural modeling," Habitat International, vol. 35, no. 2, pp. 246-253, 2011.

[50] L. Shen, X. Song, Y. Wu, S. Liao, and X. Zhang, "Interpretive structural modeling based factor analysis on the implementation of emission trading system in the Chinese building sector," Journal of Cleaner Production, vol. 127, pp. 214-227, 2016.

[51] Q. Yanbo, J. Guanghui, T. Yaya, S. Shang Ran, W. Shuwen, and L. Yuling, "Urban-rural construction land transition (URCLT) in Shandong province of China: features measurement and mechanism exploration," Habitat International, vol. 86, pp. 101-115, 2019.

[52] L. Tian, "Land use dynamics driven by rural industrialization and land finance in the peri-urban areas of China: "The examples of Jiangyin and Shunde"' Land Use Policy, vol. 45, pp. 117-127, 2015.

[53] Shandong Construction Industry Deepening Reform to a New High, Construction (In Chinese), 2019.

[54] H. Liu, M. J. Skibniewski, and M. Wang, "Identification and hierarchical structure of critical success factors for innovation in construction projects: Chinese perspective," Journal of Civil Engineering and Management, vol. 22, no. 3, pp. 401-416, 2015.

[55] F. Z. Luo, M. L. Xing, and Y. H. Han, "Structural model construction and empirical study of core competitiveness of construction enterprises," Journal of Xi'an University of Architecture and Technology (Natural Science Edition), vol. 47, no. 6, pp. 910-914, 2015, in Chinese.

[56] X. Wang, H. Pan, and B. Liu, "Research on competitiveness evaluation of China's regional construction industry based on cloud model," Journal of Shanxi University of Finance and Economics, vol. 7, pp. 55-56, 2012, in Chinese.

[57] M. Lu and L. Y. Pei, "Based on matter-element analysis theory, the evaluation of EPC engineering contracting capacity of construction enterprises," Journal of Xi'an University of Architecture and Technology (Natural Science Edition), vol. 46, no. 3, pp. 441-448, 2014, in Chinese.

[58] H. Pan, X. Q. Wang, and B. S. Liu, "Research on the influence mechanism of China's construction industry competitiveness based on SEM," Journal of Shanxi University of Finance and Economics, vol. 35, no. 5, pp. 63-73, 2013, in Chinese.

[59] L. Y. Shen, W. Lu, Q. Shen, and H. Li, "A computer-aided decision support system for assessing a contractor's competitiveness," Automation in Construction, vol. 12, no. 5, pp. 577-587, 2003.
[60] B. Liu, T. Huo, J. Meng, J. Gong, Q. Shen, and T. Sun, "Identification of key contractor characteristic factors that affect project success under different project delivery systems: empirical analysis based on a group of data from China," Journal of Management in Engineering, vol. 32, no. 1, Article ID 05015003, 2016.

[61] A. Mohebifar, M. H. Sobhiyah, and S. Haghbin, "Enhancing general contractors capacities with collaborative networks," Organization, Technology \& Management in Construction: An International Journal, vol. 5, no. 3, pp. 784-790, 2013.

[62] W. Alzober and A. R. Yaakub, "Integrated model for selection the prequalification criteria of contractor," Lecture Notes on Software Engineering, vol. 2, no. 3, pp. 233-237, 2014.

[63] M. Huda, "Implementation of PMBOK 5th standard to improve the performance and competitiveness of contractor companies," International Journal of Civil Engineering and Technology (IJCIET), vol. 9, no. 6, pp. 1256-1266, 2018.

[64] M. R. Afshar, Y. Alipouri, M. H. Sebt, and W. T. Chan, "A type-2 fuzzy set model for contractor prequalification," Automation in Construction, vol. 84, pp. 356-366, 2017.

[65] P. Rashvand, M. Z. A. Majid, M. Baniahmadi, and F. Ghavamirad, "Contractor selection at prequalification stage: current evaluation and shortcomings," Jurnal Teknologi, vol. 77, no. 16, 2015.

[66] M. K. Rao, V. Kumar, and P. R. Kumar, "Optimal contractor selection in construction industry: the fuzzy way," Journal of The Institution of Engineers (India): Series A, vol. 99, no. 1, pp. 67-78, 2018.

[67] N. Malahayati, "The main factor affecting the competitiveness of contractor company," in IOP Conference Series: Materials Science and Engineering, IOP Publishing, Bristol, UK, 2018.

[68] D. J. Watt, B. Kayis, and K. Willey, "The relative importance of tender evaluation and contractor selection criteria," International Journal of Project Management, vol. 28, no. 1, pp. 51-60, 2010.

[69] W. Zhang, Y. Yang, and W. Liu, "Contractor evaluation model for large project based on grey relevancy," Applied Mechanics and Materials, vol. 357-360, pp. 2384-2387, 2013.

[70] Y. Du, "Research on the development status of international project contracting in China under the background of one belt and one road," Modern Marketing, vol. 27, no. 10, p. 74, 2019, in Chinese.

[71] N.-H. Pan, Y.-Y. Lin, and N.-F. Pan, "Enhancing construction project supply chains and performance evaluation methods: a case study of a bridge construction project," Canadian Journal of Civil Engineering, vol. 37, no. 8, pp. 1094-1106, 2010.

[72] X. Huang, B. L. Tan, and X. Ding, “An exploratory survey of green supply chain management in Chinese manufacturing small and medium-sized enterprises," Journal of Manufacturing Technology Management, vol. 26, no. 1, pp. 80-103, 2015.

[73] W. Jie and Y. Lin, "On implementation of the supply-side reform for optimizing the supply structure in China," Taxation Research, vol. 2, p. 2, 2016.

[74] R. d. O. A. Lopes, R. Qualharini, and E. L. Qualharinia, “The psychological contract and project management as a core competence of the organization," Procedia-Social and Behavioral Sciences, vol. 226, pp. 148-155, 2016.

[75] R. A. Perkins, "Sources of changes in design-build contracts for a governmental owner," Journal of Construction Engineering and Management, vol. 135, no. 7, pp. 588-593, 2009. 
[76] S. Beatham, C. Anumba, T. Thorpe, and I. Hedges, "KPIs: a critical appraisal of their use in construction," Benchmarking: An International Journal, vol. 11, no. 1, pp. 93-117, 2004.

[77] S. Naoum, "An overview into the concept of partnering," International Journal of Project Management, vol. 21, no. 1, pp. 71-76, 2003.

[78] A. Kazaz and S. Ulubeyli, "Strategic management practices in Turkish construction firms," Journal of Management in Engineering, vol. 25, no. 4, pp. 185-194, 2009.

[79] A. K. Mishra, "Assessment of human resource capacity of construction companies in Nepal," Journal of Advanced Research in HR \& Organizational Management, vol. 5, no. 4, pp. 14-25, 2018.

[80] O. Zwikael and E. Unger-Aviram, "HRM in project groups: the effect of project duration on team development effectiveness," International Journal of Project Management, vol. 28, no. 5, pp. 413-421, 2010.

[81] L. Li, "Exploring the project management focus in EPC general contracting mode," Petrochemical Design, vol. 35, no. 4, pp. 6-9, 2018, in Chinese.

[82] P. Galloway, "Design-build/EPC contractor's heightened risk-changes in a changing world," Journal of Legal Affairs and Dispute Resolution in Engineering and Construction, vol. 1, no. 1, pp. 7-15, 2009.

[83] B. J. Gledson and D. Greenwood, "The adoption of 4D BIM in the UK construction industry: an innovation diffusion approach," Engineering, Construction and Architectural Management, vol. 24, no. 6, pp. 950-967, 2017.

[84] P. Gong, N. Zeng, K. Ye, and M. König, "An empirical study on the acceptance of $4 \mathrm{D}$ BIM in EPC projects in China," Sustainability, vol. 11, no. 5, p. 1316, 2019.

[85] Y. Xie and Y. W. Wang, "Based on SPSS and RBF, the comprehensive evaluation model of engineering general contracting competitiveness," Journal of Harbin University of Science and Technology (Natural Science Edition), vol. 15, no. 2, pp. 106-109, 2010, in Chinese.

[86] T. Uber and G. Runeson, "Subcontractor-general contractor relationship in Australian building industry," International Journal of Project Management, vol. 3, no. 1, pp. 35-38, 1985.

[87] J. Yang, G. Q. Shen, D. S. Drew, and M. Ho, "Critical success factors for stakeholder management: construction practitioners' perspectives," Journal of Construction Engineering and Management, vol. 136, no. 7, pp. 778-786, 2010.

[88] W. Tang, Z. Li, M. Qiang, S. Wang, and Y. Lu, "Risk management of hydropower development in China," Energy, vol. 60, pp. 316-324, 2013.

[89] Y. N. Wu, Y. Huang, and Z. Y. Zhao, "Case study of national stadium in global value chain of engineering contracting," China's Industrial Economy, vol. 1, pp. 114-122, 2008, in Chinese.

[90] T. M. Toole, "Uncertainty and home builders' adoption of technological innovations," Journal of Construction Engineering and Management, vol. 124, no. 4, pp. 323-332, 1998.

[91] B. LePatner, "The industry that time forgot," Boston Globe, vol. 12, 2007.

[92] J. E. T. Eldridge and A. D. Crombie, A Sociology of Organisations (RLE: Organizations), Routledge, Abingdon, UK, 2013.

[93] E. H. Schein, Organizational Culture and Leadership, John Wiley \& Sons, Hoboken, NJ, USA, 2010.

[94] V. Abeysekera, "Understanding culture in an international construction context," Perspectives of Culture in Construction, vol. 275, pp. 39-51, 2002.
[95] L.-Y. Shen and Z.-H. Zhang, "China's urbanization challenging sustainable development," International Journal for Housing and Its Applications, vol. 26, no. 3, pp. 181-193, 2002.

[96] SCTG, "Reputation, risk and reward: the business case for sustainability in the UK property markets," 2002, http:// www.dti.gov.uk/construction/sustain/rrnr.pdf.

[97] W. Zhang, "Research on transformation and upgrading of international engineering contractors in China," Commercial Economic Research, vol. 36, pp. 118-119, 2015, in Chinese.

[98] The Ministry of Housing and Urban-Rural Construction, Measures for the General Contract Management of Projects, The Ministry of Housing and Urban-Rural Construction, Beijing, China, 2019.

[99] A. Mandal and S. Deshmukh, "Vendor selection using interpretive structural modelling (ISM)," International Journal of Operations \& Production Management, vol. 14, no. 6, pp. 52-59, 1994.

[100] L. Zhenghang, Q. Maoshan, and Y. Shangnan, "Evaluation of core Competence model of large international engineering contractors," Journal of Tsinghua University: Natural Science, vol. 55, no. 12, pp. 43-48, 2015, in Chinese.

[101] C. Homburg and C. Pflesser, "A multiple-layer model of market-oriented organizational culture: measurement issues and performance outcomes," Journal of Marketing Research, vol. 37, no. 4, pp. 449-462, 2000.

[102] K. R. Molenaar, J.-I. Park, and S. Washington, "Framework for measuring corporate safety culture and its impact on construction safety performance," Journal of Construction Engineering and Management, vol. 135, no. 6, pp. 488-496, 2009.

[103] B. Zhu, W. P. Wang, W. D. Wang, and Y. L. Zhang, "The influence of corporate culture and organizational learning on innovation performance," Soft Science, vol. 1, pp. 65-69, 2010, in Chinese.

[104] N. Ankrah, D. Proverbs, and Y. Debrah, "Factors influencing the culture of a construction project organisation," Engineering, Construction and Architectural Management, vol. 16, no. 1, pp. 26-47, 2009.

[105] G. Hofstede, G. J. Hofstede, and M. Minkov, Cultures and Organizations: Software of the Mind. Revised and Expanded, McGraw-Hill, New York, NY, USA, 3rd edition, 2010.

[106] L. D. Li, "Create an employee-centered corporate culture," Building, vol. 15, p. 8, 2019, in Chinese.

[107] A. M. Liu, Z. Shuibo, and L. Meiyung, "A framework for assessing organisational culture of Chinese construction enterprises," Engineering, Construction and Architectural Management, vol. 13, no. 4, pp. 327-342, 2006.

[108] W. E. Back and K. A. Moreau, "Cost and schedule impacts of information management on EPC process," Journal of Management in Engineering, vol. 16, no. 2, pp. 59-70, 2000.

[109] D. Olsen and J. M. Taylor, "Quantity take-off using building information modeling (BIM), and its limiting factors," Procedia Engineering, vol. 196, pp. 1098-1105, 2017.

[110] L. Du, W. Tang, C. Liu et al., "Enhancing engineer-procureconstruct project performance by partnering in international markets: perspective from Chinese construction companies," International Journal of Project Management, vol. 34, no. 1, pp. 30-43, 2016.

[111] Y. Q. Huang, J. H. Cong, and C. Wang, "Research on policy implementation effect evaluation of national sustainable development experimental zone," Environmental Management in China, vol. 12, no. 1, pp. 102-112, 2020, in Chinese. 
[112] D. Zhou and Y. Wang, "Thinking on system dynamics of the design Institute to improve the general contracting capacity of the project," Technology and Management, vol. 01, pp. 37-39, 2008, in Chinese.

[113] F. Li, "Construction enterprise transformation project general contracting is difficult where," Building, vol. 42017, in Chinese. 